\title{
A MODEL FOR HUMAN TOOTH ENAMEL CENTRAL DARK LINE ITS HRTEM IMAGES CONTRAST TRANSFER FUNCTION ANALYSIS
}

\author{
M.E. Fernández ${ }^{*}$ and J. Reyes-Gasga** \\ *Instituto Nacional de Investigaciones Nucleares, ININ. Km. 36.5 Carretera México-Toluca \\ Ocoyoacac Edo. de México 52045. MÉXICO. \\ *Instituto de Física, UNAM. Apartado Postal 20-364, 01000 México, D.F., MÉXICO.
}

When the enamel crystallites are observed with the transmission electron microscope (TEM), they exhibit a line of 1 to $1.5 \mathrm{~nm}$ wide along their centers [1,2]. This line has been named "dark line", although in reality its contrast is focus dependent: it appears dark in underfocus, disappears when the image goes through focus, and is white in overfocus. Experimental evidences suggested the presence of Octocalcium Phosphate(OCP) and Hydroxyapatite(HA) in Central Dark Line(CDL).

Experimental results indicated that $\mathrm{HA}$ and $\mathrm{OCP}$ can form an epitaxial interface, and a new calculated model [3] for the HA-OCP interface with a minimum of interfacial energy has been suggested. Nowadays the HA-OCP interface became of great biological interest in the context of mineralized tissue formation and in the study of the CDL observed in the grain of human tooth enamel. In this work, based on these considerations, we propose a model for CDL and calculated its high resolution electron microscopy (HREM) images. The optimum focus value is calculated by Contrast Transfer Function[4].The CDL was built using the program Cerius ${ }^{2}$ [5]. The Density Functional Theory was used for analyzing the energy of the CDL model.

The simulated CDL model was formed by joint two halfs unit cells of HA with one unit cell of OCP. Figure 1 shows the CDL model where the direction $\left[\begin{array}{llll}1 & \overline{2} & 1 & 0\end{array}\right]$ of HA is glue with an OCP unit cell along the direction [010]. Simulated HREM images of CDL were obtained by multislice methods using the atomic positions determined by the Cerius ${ }^{2}$ program for CDL in a PC using the SimulaTEM program[6]. The electron microscope parameters simulated corresponded to a Jeol 200CX microscope: an accelerating voltage of $200 \mathrm{KV}$, a spherical aberration coefficient of $1.2 \mathrm{~mm}$, a beam divergence half-angle of $0.5 \mathrm{mrad}$. Figure 2 shows focal series in different zone axis. The image where the CDL can be appreciated is when the defocus is $1485 \AA$ for all zone axis presented. However when the defocus is $120 \AA$ the dark line can not be appreciated.

We acknowledge the technical help from R. Hernández, P. Mexia, C. Flores, M. Aguilar, C. Zorrilla, S. Tehuacanero, L. Rendón, J. Cañetas and A. Sánchez. We thank the economical support from DGAPAUNAM.

\section{References}

[1] E.F. Bres et.al., Biophys. 1, 1105-1193 (1986).

[2] A.F. Marshall et.al., J. Dent. Res. 60, 1773-1782 (1981).

[3] M.E. Fernández et.al., Acta Crys. D. In press.

[4] X. Zou "Electron crystallography of inorganic structures. Theory and practice”. Stockholm University Publications. Stockholm, Sweden, (1995).

[5] Cerius 2 "Quantum Mechanics", April 1997 San Diego, Molecular Simulation Inc.

[6] A. Gomez et.al., Revista Latinoamericana de Metalurgia y Materiales, Vol. 21, 46-50 (2001). 


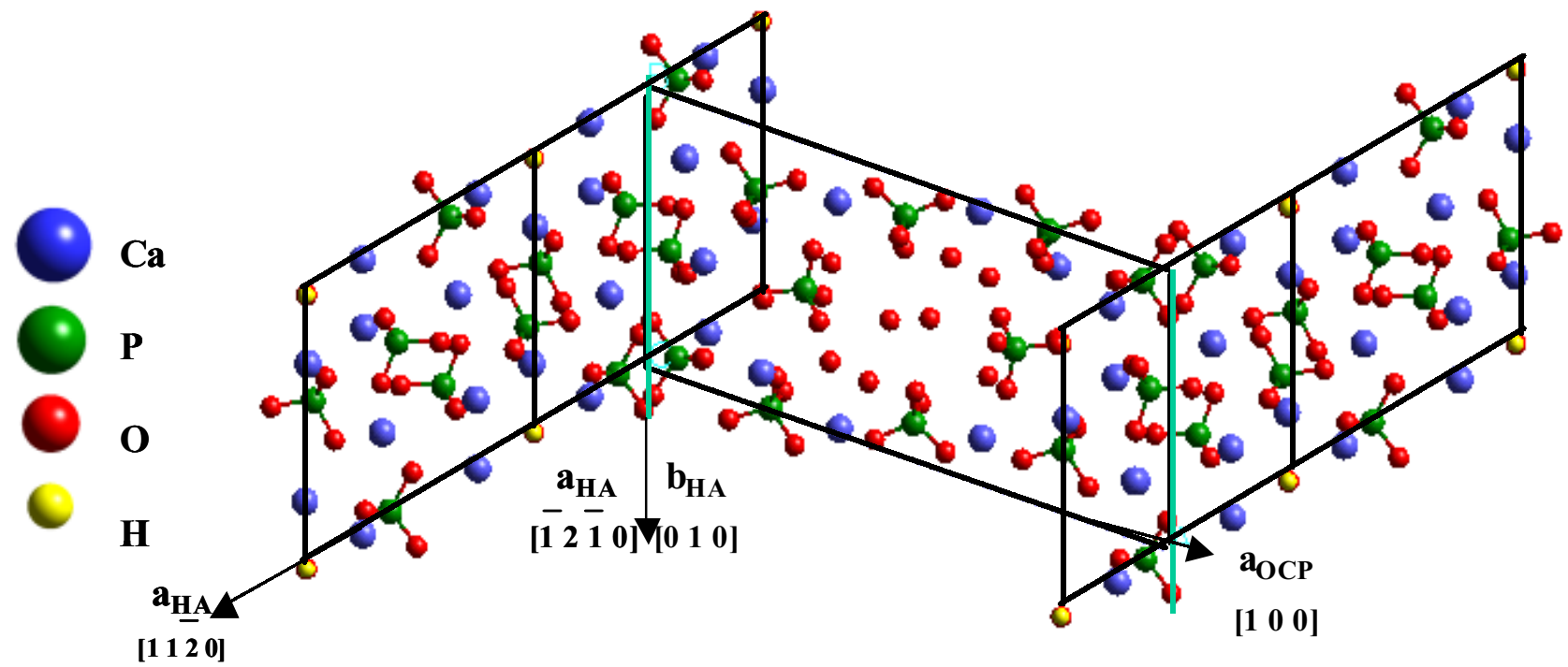

FIG. 1. Proposed model for the CDL observed in the prisms of human tooth enamel: one OCP unit cell is surrounded by two HA units cell.

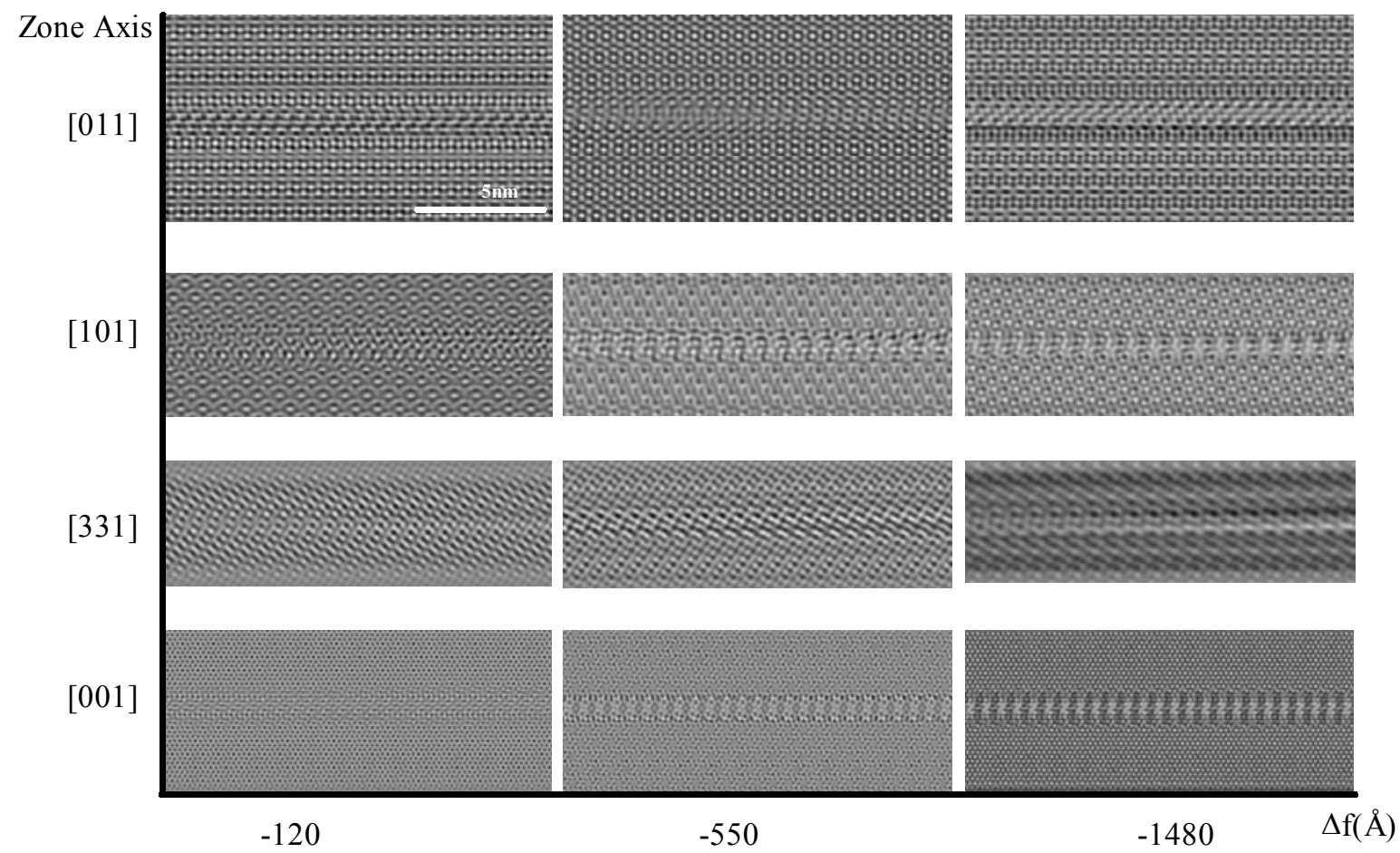

FIG. 2 Focal serie for the HREM simulated images along different zone axes for the CDL model proposed in this work. 